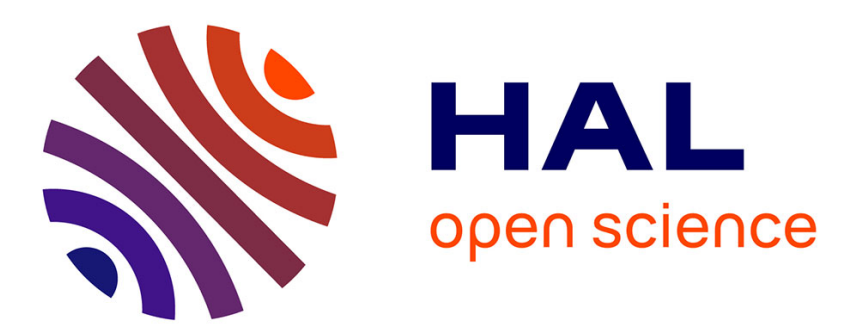

\title{
End-of-Life Product Recovery Optimization of Disassembled Parts based on Collaborative Decision-making
}

\author{
Elham Jelodari Mamaghani, Xavier Boucher
}

\section{- To cite this version:}

Elham Jelodari Mamaghani, Xavier Boucher. End-of-Life Product Recovery Optimization of Disassembled Parts based on Collaborative Decision-making. 22nd Working Conference on Virtual Enterprises (PRO-VE 2021), Nov 2021, Saint-Etienne, France. pp.179-190, 10.1007/978-3-030-85969-5_16 . emse-03338409

\section{HAL Id: emse-03338409 \\ https://hal-emse.ccsd.cnrs.fr/emse-03338409}

Submitted on 24 Nov 2021

HAL is a multi-disciplinary open access archive for the deposit and dissemination of scientific research documents, whether they are published or not. The documents may come from teaching and research institutions in France or abroad, or from public or private research centers.
L'archive ouverte pluridisciplinaire HAL, est destinée au dépôt et à la diffusion de documents scientifiques de niveau recherche, publiés ou non, émanant des établissements d'enseignement et de recherche français ou étrangers, des laboratoires publics ou privés. 


\title{
End-of-Life Product Recovery Optimization of Disassembled Parts based on Collaborative Decision- making
}

\author{
Elham Jelodari Mamaghani ${ }^{*}$, Xavier Boucher \\ Mines Saint-Etienne, Univ Clermont Auvergne, CNRS, UMR 6158 LIMOS, Institut Henri \\ Fayol Saint-Etienne France, \{Elham.jelodari,Xavier.boucher\}@emse.fr
}

\begin{abstract}
Greenhouse gas emissions are a major problem for the environment. One of the vital activities to reduce the emissions is including the circular economy (CE) approaches like reuse and remanufacture in disassembled products to recovering End-of-life products. In this paper, we consider CE in the disassembly of products not only to reduce $\mathrm{CO} 2$ emissions but also to reducing cost and improving fairness among operators. To obtain this goal, collaborative decision-making with three decision-makers (DMs) is considered to set sustainability via choosing the best EOL recovery options in the disassembly of products. Industrial managers, human resource managers, and environmental managers are three decision-makers who will collaborate to improve three indicators, which are cost, setting fairness among operators, and reducing $\mathrm{CO} 2$ emissions. To implement this collaboration, a mixed-integer multi-objective mathematical model is proposed and solved by $\mathcal{E}$-constraint. According to the results, DMs can select the best recovery options of parts to have a trade-off among indicators.
\end{abstract}

Keywords: Disassembly planning, Circular economy, Collaborative decisionmaking, End-of-life product recovery, $\mathcal{E}$-constraint

\section{Introduction and Related Works}

Increased greenhouse gases leads to global warming, climate change, and has visible effects such as sea level rise [1]. In 2015, each member of (COP 21) by participating in Paris agreement, adopted to prevent global temperature rising by taking urgent actions to protect planet [1]. One of the important strategies to GHG reduction is in the supply chain of a product assembly and recovery stage [2]. In fact, it is an alternative for manufacturing to produce new products and using new materials. Hence, recovery is an opportunity to the lack of natural resources [3]. To recover assembled products, there are major strategies that we call hereafter end of life (EOL) options. These options are recycling, reusing, and remanufacturing [4]. They can have high effects to save energy and prevention of GHG emissions compared to new products [5]. These approaches are known in the new type of economy called circular economy for waste prevention and resource efficiency [4]. In this type of industry, 
through reuse, remanufacturing or recycling at the end of life cycle, products components and materials can be get in the second life cycle. To implement these strategies, disassembly of the products is required, which is the systematic approach to separate a product into its manufactured parts [6]. Although disassembly process is costly, it can generate value (and money) by reusing, recycling or remanufacturing to prevent buying new components or materials. Furthermore, the approaches applied in disassembly process are more environmental friendly approaches can help to set the environmental axes of sustainability in the manufacturing system [4], [7]. Hence, disassembly process is inseparable function in implementing different strategies of CE. There are many methods for disassembly such as petri nets, metaheuristics algorithms, or disassembly graphs $[8 ; 9]$.

Disassembly papers can be classified to papers with and without life cycle option. In other words, some studies like [10;11] have considered life cycle option while [12] did not study the life cycle subject. The authors only focused on reduction of disassembly costs and solving the presented mathematical model with a metaheuristics algorithm. Due to the effect of GHG emissions in environment, it can be observed there are studies that have focused on the impact of life cycle option on GHG emissions in product disassembly problems $[13 ; 14]$. Multi partial disassembly by including cost, revenue, and environmental impacts was proposed by [13]. [14] proposed mixed integer mathematical model for disassembly sequence while selecting of the parts was done in terms of life cycle option. The authors considered reduction of $\mathrm{CO}_{2}$ emission in besides reduction of disassembled costs. Concerning applications for the industrial world, decision processes for End-of-life (EOL) product recovery via disassembly planning of products and circular economy approaches have been sometimes implemented on real cases like in [15; 4]. Some other researches like [16] assumed not real case but special product. The reason to include CE in industry is not only reducing GHG emissions, but also it is a new sustainability paradigm [17], which can provide the axes of sustainability like economy and environment. In order to increase the industrial added-value, the current paper proposes two advances: (i) to consider not only two but the three dimensions of sustainability by including human factors (indicator of fairness among operators) besides the environmental and economic factors; (ii) to take in consideration the necessary collaboration among several decision makers when choosing the most suitable recovery option. We consider in this paper collaboration among three decision makers; collaboration among humanresource manager, environmental manager, and industrial manager, with their distinct points of view: fairness among operators, $\mathrm{CO}_{2}$ emission reduction, and cost reduction in the recovery process sequentially. This collaborative decision making problem is modelled by a mixed integer multi-objective mathematical model and solved by $\mathcal{E}$-constraints. According to obtained solutions, decision makers can make decision considering the values of all indicators. The reminder of the paper is structured as follows. Section 2 is describes the problem definition and presenting mathematical model. Section 3 is presenting the results of mathematical model based on a set of benchmark results. In that section, the collaborative decision-making is explained. Conclusion and future research propositions are summarized in section 4 . 


\section{Problem Description and Research Model}

The research problem in this paper is making a decision by collaboration among three decision makers to determine the most suitable recovery operation (remanufacturing, reusing or disposal) for the disassembled products of EOL product by considering the quality information of EOL products. Actually, three decision makers (industrial manager, human resource manager, and environmental manager) collaborate to make the most appropriate recovery operations to achieve a minimum recovery cost and high saving rate of $\mathrm{CO}_{2}$ emissions besides setting fairness of time among operators. Hence, a mixed integer mathematical programming model is proposed to assign a recovery operation to the parts of a product to satisfy time fairness among operators, cost minimization and saving $\mathrm{CO}_{2}$ emissions. Additionally, at the end of execution, the presented model, for each disassembled part, the most suitable operations (remanufacturing, reusing or disposal) is proposed (according to constraints 11-16). Furthermore it will be determined an operation of each part is implemented by which operator. Finally, an allocation execution time for each operator is determined at the end of model's execution.

There are variety of factors with impacts on EOL strategy. In the following, a set of assumptions has been made to build the research model and the parameters and decision variables applied in the mathematical model are summarized in Table 1 and Table 2:

1. Disassembly sequence is the order of removal parts. In this paper, the optimal disassembly directions and the sequence of parts are deterministic. There is a disassembly precedence graph that is given is advance and all the nodes of the graph are indivisible nodes.

2. Remanufacturing, reusing and disposal are studied in this paper. One of the important assumptions is all of the EOL components are recoverable and one of the most suitable recovery operation (remanufacturing, reusing or disposal) is allocated to each disassembled component.

3. To simplify the mathematical model, economic information (process cost), process information (method of disassembly and its time), and quality information are presented in advance.

4. There are sufficient market demands for the products recovered by the operations (CE operations).

5. Each part of products has to be assigned to one operator to implement one operation.

Table 1. Sets and parameters of the proposed model

\begin{tabular}{|c|c|}
\hline Symbols & Description \\
\hline I & Set of parts \\
\hline $\mathrm{P}$ & Set of operators \\
\hline $\mathrm{K}=\{1,2,3\}$ & $\begin{array}{l}\text { Set of operations (1.Recycling 2. Reuse } \\
\text { 3.Remanufacture) }\end{array}$ \\
\hline$H_{i}$ & Set of predecessors for part $i \in I$ \\
\hline $\begin{array}{l}o_{i} \\
\alpha_{i}\end{array}$ & $\begin{array}{l}\text { Quality of part } i \in I \text { after operation } \\
\text { Importance (weight) of part } i \text { in the final quality of } \\
\text { product }\end{array}$ \\
\hline
\end{tabular}




\begin{tabular}{ll}
$q_{i}$ & Quality of part $i \in \mathrm{I}$ before operation \\
$q m$ & Minimum acceptance quality of a part after operation \\
$l_{i}^{1}$ & Maximum quality value required for disposal of part $\mathrm{i} \in \mathrm{I}$ \\
& Minimum quality value required for reuse of part $\mathrm{i} \in \mathrm{I}$ \\
$l_{i}^{2}$ & Minimum quality value for remanufacturing part $\mathrm{i} \in \mathrm{I}$ \\
$l_{i}^{3}$ & Usage year \\
$\mathrm{s}$ & Life expectancy of part $\mathrm{i} \in \mathrm{I}$ \\
$f_{i}$ & $\mathrm{CO}_{2}$ saving rate of part $\mathrm{i} \in \mathrm{I}$ \\
$e_{i}$ & Treatment and disposal cost of part $\mathrm{i} \in \mathrm{I}$ \\
$d_{i}$ & Reuse cost of part $\mathrm{i} \in \mathrm{I}$ \\
$c r_{i}$ & Remanufacturing cost of part $\mathrm{i} \in \mathrm{I}$ \\
$c n_{i}$ & Disassembly cost of part $\mathrm{i} \in \mathrm{I}$ \\
$c d_{i}$ & Processing time of operation $\mathrm{k} \in \mathrm{K}$ on part $\mathrm{i} \in \mathrm{I}$ by operator \\
$t_{i p k}$ & peP \\
& \\
\hline
\end{tabular}

Table 2. Decision variables of the proposed model

\begin{tabular}{ll}
\hline Symbols & Description \\
\hline$x_{i p k}$ & $\begin{array}{l}\text { 1,if and only if operation } \mathrm{k} \in \mathrm{K} \text { is done } \\
\text { by operator } \mathrm{p} \in \mathrm{P} \text { on the part } \mathrm{i} \in \mathrm{I} ; 0, \\
\\
\text { otherwise }\end{array}$ \\
$y_{i j p}$ & 1, if and only if operator $\mathrm{p} \in \mathrm{P}$ \\
& operates on part $\mathrm{i} \in \mathrm{I}$ then part $\mathrm{j} \in \mathrm{I} ;$ \\
$u_{i}$ & $\begin{array}{l}\text {,otherwise } \\
\text { Starting time of an operation on part }\end{array}$ \\
$C_{\max }$ & $\begin{array}{l}\mathrm{i} \in \mathrm{I} \\
\text { Variable used to balance the operation } \\
\text { time of operators }\end{array}$ \\
\hline
\end{tabular}

In the following, the proposed mixed integer multi-objective mathematical programming model is presented. The constraints 11-20 are described at Appendix A. In first objective function (adopted from [4] due to limited page readers can refer to that paper), all costs like disassembly cost and the cost of recovery operations (reuse, disposal, and remanufacturing) are minimized. This objective function is an indicator, which an industrial manger makes decision about it.

$$
\min Z_{2}=C_{\max }
$$

Objective function (2) besides equation (10) guarantee the time fairness among operators Thus, this is an indicator considered by a human resource manager. This function, together with equations (7)-(10), can determine the starting time of operation by each operator on each part of the disassembled product.

Objective function (3) adopted from [4], associated to the environmental manager, maximizes the saving rate of $\mathrm{CO}_{2}$ produced in remanufacturing and reusing process Constraints are:

Equations (4) adopted from [4] induce that, on each part of disassembled product, an operator implements one operation. 


$$
\begin{array}{ll}
2 \times\left(y_{i j p}+y_{j i p}\right) \leq \sum_{k \in K}\left(x_{i p k}+x_{j p k}\right) & \forall i, j \in I, i \neq j, \forall p \in P \\
\left(y_{i j p}+y_{j i p}\right) \geq \sum_{k \in K}\left(x_{i p k}+x_{j p k}\right)-1 & \forall i, j \in I, i \neq j, \forall p \in P
\end{array}
$$

Equations (5) and (6) indicate that an operator cannot work simultaneously on a part and its predecessor (two operations cannot be done by an operator).

$$
u_{j} \geq u_{i}+\sum_{p \in P} \sum_{k \in K} t_{i p k} x_{i p k} \quad \forall j \in I, \forall i \in H_{j}
$$

Constraints (7) show the starting time of an operation on a part and its predecessor part.

$$
\begin{array}{ll}
u_{j} \geq u_{i}+\sum_{k \in K} t_{i p k} x_{i p k}-M\left(1-y_{i j p}\right) & \forall i, j \in I, i \neq j, \forall p \in P \\
u_{i} \geq u_{j}+\sum_{k \in K} t_{j p k} x_{j p k}-M\left(1-y_{j i p}\right) & \forall i, j \in I, i \neq j, \forall p \in P
\end{array}
$$

Constraints (8) and (9) are working together and show the starting operation time of an operator on the allocated parts according to the position of each part.

$$
C_{\max } \geq u_{i}+\sum_{k \in K} t_{i p k} x_{i p k} \quad \forall i \in I, \forall p \in P
$$

Constraints (10) point to the maximum of working time for each operator.

\section{Experimental Results}

The proposed model that is mixed-integer linear programming is solved by $\varepsilon$ constraints method. Since real disassembly enterprises are small, it is not needed to solve the model with heuristics or metaheuristics algorithms even though the problem is NP-hard [16]. In fact, the firms need to solve easily the problem in their business by common commercial solvers instead of complicated algorithms. Data applied to solve the problem are chosen from [4] and adjust according to the considered problem. The solution approach is $E$-constraints method that is implemented by GAMS 12.6. The results have been illustrated in Table 1, Fig 1 and Fig 2 as the first figure shows the relation between costs and rate of saving $\mathrm{CO}_{2}$ emission and in the second figure costs and time fairness of operators has been depicted. According to Fig 1, industrial manager and environmental manager can make decision about the impact of increasing (or reducing) costs and saving rate of $\mathrm{CO}_{2}$ emission. As it can be understood from the figure, the saving rate of $\mathrm{CO}_{2}$ emission increases when more money is spent. It means that, selection of remanufacturing operation or reusing operation can reduce GHG emission. Therefore, the two managers can make decision about the costs and the saving rate of $\mathrm{CO}_{2}$ emission. To observe the effect of costs on the time fairness of operators, Fig 2 can be used. It is clear that when the number of operators is increased the time fairness is improved while the value of cost is increased. Table 1. shows the assignment of operators and operations to each parts. 
Hence, this model gives an idea to industrial manager and human resource manager how they can handle time of operators and total costs of recovery operations.

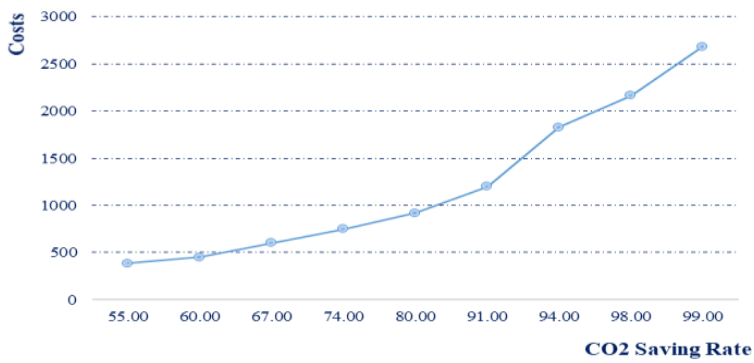

Figure 1. Behaviors of the disassembly parts selection of $\mathrm{CO}_{2}$ saving rate and recovery cost

Table 1. Recovery operation on each parts of [4]

\begin{tabular}{|c|c|c|}
\hline Number of a part & operation & Operator \\
\hline 1 & 3 & 1 \\
\hline 2 & 3 & 2 \\
\hline 3 & 1 & 1 \\
\hline 4 & 2 & 1 \\
\hline 5 & 2 & 2 \\
\hline 6 & 2 & 2 \\
\hline 7 & 2 & 1 \\
\hline 8 & 1 & 1 \\
\hline 9 & 2 & 1 \\
\hline 10 & 2 & 1 \\
\hline 11 & 2 & 1 \\
\hline 12 & 2 & 2 \\
\hline 13 & 2 & 1 \\
\hline 14 & 2 & \\
\hline
\end{tabular}

है

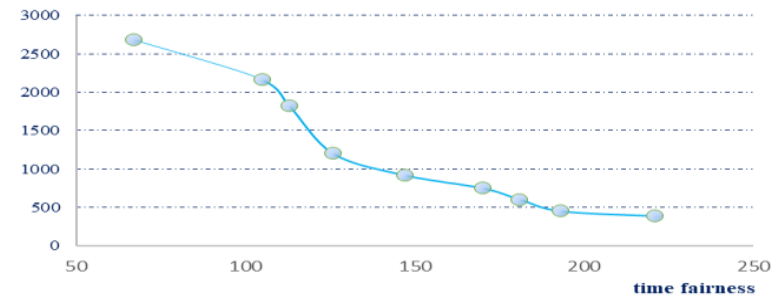

Figure 2. Behaviors of the disassembly parts selection in terms of recovery cost and time fairness

\section{Discussion and Conclusion}

Discussion on collaborative decision-making

This study suggested a life cycle option selection of disassembly parts by collaborative decision-making. Each part is selected for disposal, reuse or remanufacturing and decision makers by collaboration can make decision to minimize 
cost, maximize $\mathrm{CO}_{2}$ saving rate, and maximize the fairness among operators. In case of convergence between these criteria, the sustainability in the disassembly part selection can be achieved. In other words, by including collaboration among three decision makers, three aspects of sustainability (providing economic concept, environmental issues, and social factors) can be satisfied. A first perspective is thus to further model and study collaborative decision process. Through collaboration each decision makers could become aware of the effect of each objective function's value on the other objection functions. In addition, by analyzing the increase and reduction of the respective values of each function, decision makers could study the impacts on the choice of an appropriate recovery operation.

Conclusion and perspectives

In this paper, a mixed integer multi-objective mathematical model was proposed to recovery of a product parts after disassembly through circular economy operations. The objective is to minimize all the costs besides increasing $\mathrm{CO}_{2}$ emission rate, and maximization of fairness among operators (in terms of time). The problem was solved by $\mathcal{E}$-constraints method to obtain the most suitable recovery operations. However, there are a number of limitations that should be considered in the future works. The first limitation is not considering reliability of each part, while the reliability should be included in the usage years. Second proposition is solving the problem for large size instances with metaheuristics algorithms. Finally, quality manager as a next decision maker can be cooperated in the decision-making process to maximize the total quality of by choosing of the most suitable operations at the EOL.

\section{References}

1. United Nations, 2015. (online) https://sustainabledevelopment.un.org/topics/climatechange, Accessed date: 30 April (2018).

2. Kokubu, K., Itsubo, N., Nakajima, M., Yamada, T.: Low Carbon Supply Chain Management. Chuokeizai-sha Inc. Tokyo, (2015).

3. Ilgin, M.A., Gupta, S.M.: Remanufacturing Modeling and Analysis. CRC Press, Boca Raton, (2012).

4. Hasegawa, S., Kinoshita, Y., Yamada, T., Bracke, S.: Life cycle option selection of disassembly parts for material-based $\mathrm{CO} 2$ saving rate and recovery cost: Analysis of different market value and labor cost for reused parts in German and Japanese cases. Int. J. Prod. Econo, 213, 229-242, (2019).

5. Inoue, M., Takahashi, S., Fujita, M., Mori, T., Tamaki, M., Suzuki, S., Hayakawa, A.: Quantitative estimate of $\mathrm{CO} 2$ emission reduction from reuse of automobile parts in Japan. Int. J. Supply Chain Manag. 6 (4), (2017)

6. Lambert, A.J.D., Gupta, S.M.: Disassembly Modeling for Assembly, Maintenance Reuse, and Recycling. CRC Press, Boca Raton, (2005).

7. European Commission, 2015. Available at: https://ec.europa.eu/clima/policies/international/negotiations/paris_en, Accessed date: 10 May (2018).

8. Ren, Y., Tian, G., Zhao, F., Yu, D., Zhang, C.: Selective cooperative disassembly planning based on multi-objective discrete artificial bee colony algorithm. Eng. Appl. Artif. Intell. 64, 415-431, (2017).

9. Wang, H., Penga, Q., Zhangb, J., Gub, P. : Selective disassembly planning for the end-oflife product. Procedia CIRP 60, 512-517, (2017).

10. Igarashi, K., Yamada, T., Gupta, S.M., Inoue, M., Itsubo, N.: Disassembly system modeling and design with parts selection for cost, recycling and $\mathrm{CO} 2$ saving rates using multi criteria optimization. J. Manuf. Syst. 38, 151-164, (2016). 
11. Smith, S., Hsu, L.Y., Smith, G.C.: Partial disassembly sequence planning based on costbenefit analysis. J. Clean. Prod. 139, 729-739, (2016).

12. Hasegawa, S., Kinoshita, Y., Yamada, T., Inoue, M., Bracke, S.: Disassembly reuse Part Selection for recovery rate and cost with lifetime analysis. Int. J. Autom. Technol. 12 (6) $822-832,(2018)$.

13. Rickli, J. 1., Camelio, J.A.: Partial disassembly sequencing considering acquired end-oflife product age distributions. Int. J. Prod. Res. 52 (7), 496-512, (2014).

14. Riggs, R.J., Jin, X., Hu, J.: Two-stage sequence generation for partial disassembly of products with sequence dependent task times. Procedia CIRP 29, 698-703, (2015).

15. Jun, H.B., Cusin, M, Kiritsis, D., Xirouchakis, P.: A Multi-Objective Evolutionary Algorithm for EOL Product Recovery Optimization: Turbocharger Case Study. Int. J. Pro. Res. 45 (18-19), (2007).

16. Meng, K., Lou, P., Peng, X., Prybutok, V.: An Improved Co-Evolutionary Algorithm for Green Manufacturing by Integration of Recovery Option Selection and Disassembly Planning for End-Of-Life Products. Int. J. Pro. Res. 54 (18), (2016).

17. Geissdoerfer, M., Savaget, P., Bocken, N.M. and Hultink, E.J. The Circular Economy-A new sustainability paradigm?. J. Clean. Prod, 143, 757-768, (2017).

\section{Appendix A}

$$
\sum_{p \in P} q_{i} x_{i p 1} \leq l_{i}^{2} \quad \forall i \in I
$$

Equations (11) confirm that a part with above a predetermined quality is not candidate to be disposed.

$$
\sum_{p \in P} q_{i} x_{i p 2} \geq l_{i}^{3} \quad \forall i \in I
$$

Equations (12) indicate if the quality of a part is lower than a certain quality level, that part cannot be reused.

$$
\begin{aligned}
& \sum_{p \in P} q_{i} x_{i p 3} \geq l_{i}^{4} \quad \forall i \in I \\
& \sum_{p \in P} q_{i} x_{i p 3} \leq 1 \quad \forall i \in I
\end{aligned}
$$

Equations (13) and (14) define the quality of a part that has can be candidated to remanufacturing recovery operation.

$$
o_{i}=\sum_{p \in P} q_{i} x_{i p 2}+1-\sum_{p \in P} x_{i p 2} \quad \forall i \in I
$$

Equations (15) imply to the quality of a part after reuse operation.

$$
\sum_{i \in I} o_{i} \alpha_{i} \geq q m \quad \forall i \in I
$$

Equations (16) confirm the total obtained quality should be bigger than minimum acceptable quality. 